\title{
Performance Evaluation of a Pressurized Cooking Stove Using Vegetable Cooking Oils as Fuel
}

\author{
Suhartono", Tiara Arini Putri", Lutfi Fauziah ${ }^{\#}$ \\ ${ }^{\#}$ Department of Chemical Engineering, Universitas Jenderal Achmad Yani, Cimahi 40533, Indonesia \\ E-mail: suhartono@lecture.unjani.ac.id
}

\begin{abstract}
Liquid petroleum gas (LPG) and kerosene can be substituted by vegetable cooking oils (VCOs) as fuel using the pressurized cooking stove. The higher of ignition values, density, and viscosity of VCOs compared to other oils, such as kerosene was a basic consideration to modify the vegetable oil pressure stove (VOPS). The VOPS design employed with spiral coil pipeline as oil preheater that was intended to reduce viscosity and ignition values of VCOs. The spiral coil pipeline in this VOPS will auto preheat the oil to decrease its viscosity and to produce smaller droplets before being combusted. The performance indicators fuel/stove/vessel combination were conducted by measurements, calculations, and experiments. The performance parameters were represented by fuel characteristic, oil droplet diameter, combustion flame and fuel consumption. The main purpose of this experiment was to study the use of VCOs as alternative fuels as well as combustion performance and economic evaluation. The experiment was conducted by using three kinds of VCOs as fuel; used vegetable oil (UCO), crude VCO and fresh UCO on VOPS. The VCOs could be burned in a red-bluish flame with a maximum flame temperature of flue gases of $1100{ }^{\circ} \mathrm{C}, 1042{ }^{\circ} \mathrm{C}$, and $920{ }^{\circ} \mathrm{C}$, respectively. Atomization of all VCOs could produce fuel droplets diameter of $155 \mu \mathrm{m}-650 \mu \mathrm{m}$ and lower viscosity and lower ignition values of the fuels. The efficiency of the VOPS was $20 \%-32 \%$ calculated by the fuel consumption rate (FCR) of $\pm 1.50 \mathrm{~L} / \mathrm{h}$ and gave the economic values were cheaper than using kerosene or LPG as fuel.
\end{abstract}

Keywords - VCOs; VOPS; ignition; flame; droplet

\section{INTRODUCTION}

Edible oils such as palm oil, coconut oil, and other vegetable cooking oils (VCOs) is a basic household needs in everyday life to cook for urban and rural communities in Indonesia. Quantitatively, there are a lot of cooking oil needed for frying foods in households and small industries that spread throughout the region. For example, in West Bandung District, cooking oil consumption for 22 small and medium industries in producing fried food is around 18 tons/year. About 8 tons/year of used cooking oil (UCO) can be produced as the waste from these industries [1].

The increased consumption of cooking oil resulting in increasing UCO as well. Nevertheless, up to the present time, there are still many Indonesian people who use cooking oil repeatedly without processing it first. Whereas cooking oil should not be used more than three times, repeated use of cooking oil is harmful to human health, because it is carcinogenic [2], [3]. However, utilizing UCO properly and correctly is still not optimal. Therefore, it is necessary to handle UCO properly in order to give beneficial and to avoid detriment of human health and environmental aspects [3].

On the other hand, the use of LPG as a source of fuel is common in the small industry. The need of LPG for every small industry is about $30 \mathrm{~kg} /$ day [4]. UCO can be used as fuel to replace LPG to meet the needs of those small industries. Among of biofuels utilization as fuel is UCO using a pressurized stove. Somehow, the ignition point of UCO $\left(175{ }^{\circ} \mathrm{C}\right)$ is higher than kerosene $\left(55^{\circ} \mathrm{C}\right)$ and the viscosity of UCO can be up to about 30 to 50 times higher than that of kerosene as reported by formerly researchers [5]-[9]. This means that the operation of the UCO is more difficult than the kerosene due to the viscose and its ease of ignition. High ignition points of UCO and other VCOs as fuel closely related to high viscosity need special modification of pressurized cooking stove in its utilization. According to Ejilah [5], preheating of the UCO reduced the viscosity which resulted in improved atomization property. Some of the researchers have already developed alternative stoves to improve the efficiency with different fuels. Commonly, there are two types of stoves: the conventional stove or the wick stove and the pressurized stove. The pressurized stove has been used for studying the thermal efficiency of vegetable oil fuels. The thermal efficiency of this pressurized stove is higher when compared with wick stoves. The difference of pressurized cooking stove in this study to the results of previous research is the advantage of the pipe fittings spiral coil component that serve as auto oil preheating and a nozzle which serves as sprayer of oil. 
Spiral-shaped pipe coil is designed so that the UCO as fuel can be preheated first before ignited. Any kind of VCOs such as crude palm oil, fresh palm oil etc. also can be used as fuel using this pressurized cooking stove design. By adequately preheated in the spiral coil pipe, the fuel will come out in the vapor phase (droplet) and its physical parameters can reach values very close to that of kerosene. Ambient air will diffuse directly into that droplet which is expected to improve their combustion performance and thus reducing ignition values and incomplete combustion. The innovation of this pressurized cooking stove design is predicted to give a good VCOs combustion and higher thermal efficiency compared to the usual pressurized stove.

This work focuses on the possibility of combustion UCO as the alternative fuel to meet the need for energy in the small industry in our country. The present work demonstrated a comparative study for combustion characteristics between kerosene and VCOs, namely UCO, fresh VCO and crude VCO, to determine its usefulness as an alternative fuel. The combustion flame temperature, structure, and color of flame were observed. The prediction of fuel droplet diameter and heating value, the thermal efficiency calculation as well as economic evaluation were also accomplished in this study.

\section{MATERIAL AND METHOD}

\section{A. Properties of VCOs as Fuel}

Characteristics of any fuel are very important from the point of deciding whether the fuel can be used for desired application or not. A number of researchers reported some characteristics of density, viscosity, flash point and heating value of the VCOs, UCO, and kerosene as fuel are shown in Table 1 [5]-[11]. Viscosity is one of the important properties of these fuels, because of the immediate and visible effects that can occur when values of this parameter are not suitable. The high-value viscosity of the VCOs for fuel utilization using vegetable cooking oil pressurized stove (VOPS) are the cause of incomplete combustion and of the formation of deposits on the burner nozzle (spoiler).

Some of the UCO's parameters are in close to the standard values of the kerosene. Especially the viscosity of UCO is almost similar to the viscosity of kerosene. Toscano [9] and Blin [10] reported, that during frying, VCO undergoes various physical and chemical changes, include free fatty acid and some polymerized triglycerides which increase the molecular mass and reduce the volatility of the oil [12]. Therefore, fatty acid esters obtained from frying oil influences the VCO characteristics, such as reducing the viscosity of VCO [9], [10].

On the other hand, the feedstock coming from is one of the alternative sources of other oils. Because UCO oil is easy to collect from households and small industries in West Bandung District in our country. Hence, by using these UCO as fuel to substitute LPG or kerosene be able to reduce the cost production for those small industries. Many individuals dispose and those small industries waste UCO directly to the environment especially in rural area. So that, the UCO utilization as fuel is an effective way to prevent environmental pollution and to reduce the production cost of those small industries.
TABLE I

CHARACTERISTIC OF $\mathrm{VCO}_{s}$ AND KEROSENE AS FUEL

\begin{tabular}{|c|c|c|c|c|}
\hline Fuel & $\begin{array}{l}\text { Density } \\
\mathrm{kg} / \mathrm{m}^{3} \\
\text { at } 15 \\
\left({ }^{\circ} \mathrm{C}\right)\end{array}$ & $\begin{array}{l}\text { Kinemati } \\
\text { c } \\
\text { viscosity } \\
\text { (cSt) }\end{array}$ & $\begin{array}{c}\text { Flash } \\
\text { point }{ }^{\circ} \mathrm{C}\end{array}$ & $\begin{array}{c}\text { Heatin } \\
\text { g } \\
\text { Value } \\
\text { MJ/kg }\end{array}$ \\
\hline Coconut oil & 918 & $27^{\mathrm{c}}$ & $270-300$ & 37.1 \\
\hline Corn oil & 910 & $31-35^{b}$ & 277 & 39.5 \\
\hline Palm oil & 918 & $401-45^{\mathrm{c}}$ & 267 & 39.5 \\
\hline Peanut oil & 903 & $40^{\mathrm{c}}$ & 271 & 39.8 \\
\hline Soybean oil & 914 & $29^{c}-33^{b}$ & 254 & 39.6 \\
\hline $\begin{array}{l}\text { Sunflower } \\
\text { oil }\end{array}$ & 916 & $34^{\mathrm{b}}-36^{\mathrm{c}}$ & 274 & 39.6 \\
\hline $\mathrm{UCO}$ & 876 & $3.66^{\mathrm{c}}$ & 160 & 39.8 \\
\hline Kerosene & $775-840$ & $2.40^{\mathrm{a}}$ & $38-72{ }^{\circ} \mathrm{C}$ & 38.1 \\
\hline
\end{tabular}

${ }^{\mathrm{a}}$ kinematic viscosity at $30^{\circ} \mathrm{C}$, ${ }^{b}$ kinematic viscosity at $37.8^{\circ} \mathrm{C}$ and

kinematic viscosity at $40^{\circ} \mathrm{C}$

As seen in Table 1, the kinematic viscosity of UCO is about 12 times greater than that of others VCOs but is almost similar to kerosene. While its density is about the same for all kind of fuel oil. These properties play a vital role in the combustion. In order to reduce the kinematic viscosity and specific gravity of VCOs, some modification of the pressurized stove is needed. The spiral coil line assembled as auto oil preheater in a pressurized stove is a technique to reduce the kinematic viscosity and specific gravity of VCOs before combustion occurs. This method is relatively easy to carry out, and by this way, the good oil combustion will be obtained.

The flash point of VCOs ranges from 160 to $300^{\circ} \mathrm{C}$, compared to about $72^{\circ} \mathrm{C}$ for kerosene [4]-[11]. The flash point of UCO is closer to kerosene, as shown in Table 1. This means UCO utilization as fuel is much better due to its easy ignition. The ignition point is relatively close to flash point. Flash Point temperature is the temperature at which the fuel will produce a flame (burning) when subjected to the fire source. However, these conditions only last a few moments. Having raised the fire, the fire will extinct in a short time later. Whereas, the ignition point is the minimum temperature at which the vapors of a fuel catch fire if in contact with a flame. This property is also called as fire point, is the temperature at which the fire will flare continuously from the fuel that has been subjected to the fire source. As long as fuel and oxygen to the environment are available, then the fire will continue to burn.

In the liquid oil tests, the temperature increase slows down after the oil begins to emit smoke and pyrolyze. But once boiling begins, the temperature increases more rapidly as the boiling and smoke emission becomes more intense. When this is observed, the oil is becoming close to its ignition point.

The flash point temperature of liquid oil corresponds roughly to a vapor pressure of 3-5 $\mathrm{mm} \mathrm{Hg}$. When a small flame (ignition source) is applied to the oil's surface this vaporous mixture will burn momentarily and then extinguish if the critical temperature has been reached. Continued heating of the liquid oil (typically about $10{ }^{\circ} \mathrm{C}$ above the flash point temperature) will cause the "fire point" to be reached at which a sustained flame results (longer than four seconds). 
The viscosity of a liquid affects its fire point. Viscosity is one of the most important physical properties of a fluid system. Viscosity changes with shear rate, temperature, pressure, moisture, and concentration [13]. The viscosity of a fluid is a measure of its resistance to flow or movement. The more viscous a liquid, the more resistant it is against the flow. Viscosity depends on temperature and decreases as the temperature increases. Higher the viscosity results from low volatility and poor atomization of oil in the pressurized stove, that results in complete combustion and ultimately carbon deposit on nozzle spoiler as well as in the combustion pipeline. Most often, thicker liquid oils take longer to ignite. Viscosity and ignition point are both physical properties that are determined by intermolecular forces. Although viscosity and ignition point do not directly affect each other, there is a correlation based on the strength of these intermolecular forces. The flow resistance of the oil is also due to intermolecular bond strength between liquid molecules, the higher the bond strength, the higher the viscosity. The densities and viscosities of oils decreased nonlinearly with temperature, respectively [13].

\section{B. The Modified Pressurized Stove}

The cooking stove consists of 5 liters of a barrel cylindrical-shaped fuel vessel and spiral pipeline mechanism exposed, that serves as auto oil preheater and the burner spoiler nozzle to produce oil droplets (vaporizer). This modified pressurized cooking stove was based on the methods to vaporize and spray under pressure as shown in Fig. 1

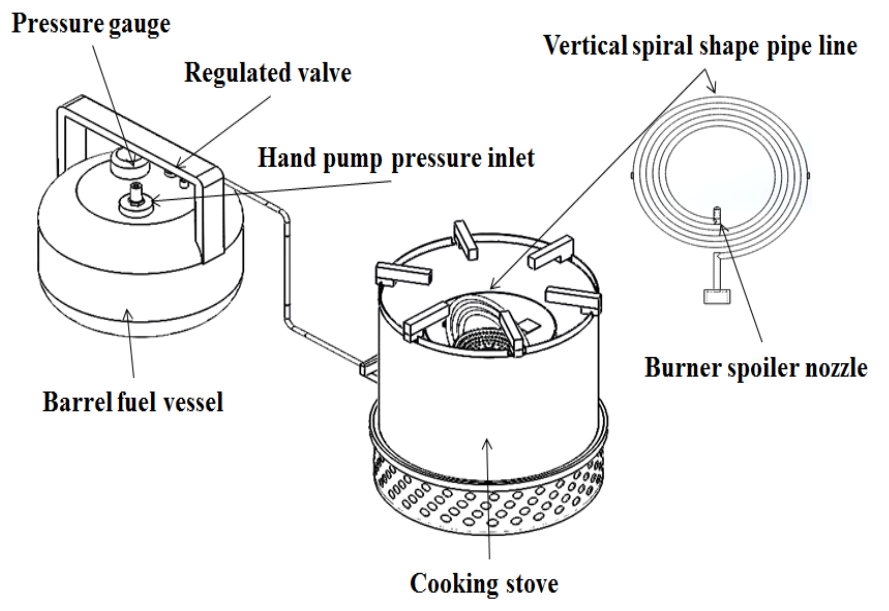

Fig. 1 Sketch of modified pressurized cooking stove

The feasibility of VCOs and UCO utilized as fuel in direct combustion using this modified pressurized cooking stove is the aim of this work. This stove was designed to decrease oil viscosity and to produce smaller oil droplets in order to behave like kerosene. This design is a low-price technology for domestic cooking use. The stove can be used in either indoor or outdoor cooking.

\section{Experimental Methods}

The VCOs and UCO in barrel fuel vessel were used directly as a fuel. This oil was then forced under pressure through a spiral pipeline to burner spoiler nozzle by keeping the fuel pressure vessel created by a hand pump integrated into the tank at around 3 bars. The fuel flow rate was regulated with the valve installed in the pipeline. A small amount of $10 \mathrm{~mL}, 15 \mathrm{~mL}$ and $20 \mathrm{~mL}$ alcohol burned in a preheating dish beneath the fuel pipeline (vaporizer) was needed to ignite this fuel. Then the heat from the flame heated the fuel in the pipeline. The coming out of fuel droplets (vaporized fuel) sprayed mixed with ambient air was ignited and the combustion process was initiated in a sootless and reddish blue flame. This flame heated the fuel in pipe continuously via a loop of the fuel spiral pipeline passing through the flame. Additional pumping increases and keeps the vessel pressure and makes the flame larger. The decreasing of the pressure in the fuel vessel reduced the flame size. According to Ejilah's experiment [7], the combustion behavior of a pressurized kerosene cook stove provided a more thermal efficiency, the flame temperature also increases without sooty emissions.

\section{Performance Indicators}

The measurements, calculations, and experiments were conducted to obtain performance indicators fuel/stove/vessel combination. In present work, three common household cooking oils of UCO, crude VCO, and fresh VCO were used as fuel. The properties of those VCOs used for this experiment are density and viscosity. The density of VCOs was measured according to ASTM D1298 methods. The measurements of viscosity were carried out at a temperature of $25^{\circ} \mathrm{C}-70^{\circ} \mathrm{C}$ in triplicates and the average values were used. The oil was put in a $50 \mathrm{ml}$ density bottle and weighed on a mass balance. The density was then obtained as given in equation (1) [13].

$$
\rho_{\mathrm{L}}=\frac{\left(\mathrm{m}_{\mathrm{BL}}-\mathrm{m}_{\mathrm{B}}\right)}{\mathrm{V}_{\mathrm{L}}}
$$

Where $\rho_{\mathrm{L}}$ is the density of the liquid $\left(\mathrm{g} / \mathrm{cm}^{3}\right) ; \mathrm{m}_{\mathrm{BL}}$, the mass of bottle and liquid $(\mathrm{g}) ; \mathrm{m}_{\mathrm{B}}$, the mass of bottle only and $\mathrm{V}_{\mathrm{L}}$ is the volume of the liquid $\left(\mathrm{cm}^{3}\right)$.

The viscosity of VCO was measured using the method suggested by ASTM D445. The viscosity of the VCO was measured by using a Cannon-Fenske capillary viscometer by putting the oil in a breaker while the breaker was put in a water bath at a temperature of $25{ }^{\circ} \mathrm{C}$ to $70{ }^{\circ} \mathrm{C}$ in triplicates and the average values were used. The viscosity is obtained from the following equation (2);

$$
v_{\mathrm{f}}=\mathrm{t} \cdot \mathrm{c}_{0}(\mathrm{~T})
$$

$v_{\mathrm{L}}$ being the kinematic viscosity in centistokes, $t$ the flow time expressed in seconds and $c_{0}(T)$ the characteristic calibration constant of each viscometer measured at the working temperature [14]. This viscosity was also evaluated according to correlation between kinematic viscosity and density of vegetable oils using equation (3);

$$
v_{f}=-0.7328 \rho_{L}+938.57
$$

Literatur shows that viscosity of vegetable oils is related to chemical composition and chemical structure of oils [10], [15]. Meanwhile, there is a relationship between the 
chemical structure and composition of vegetable oils and heating value [17]. Therefore, heating values of oils were determined by an easier, faster and cost effective way of equation (4) suggested by Dermibas [16], [17].

$$
\mathrm{HV}=0.0137 v_{\mathrm{f}}+38.053
$$

\section{$\mathrm{HV}$ being heating value in $\mathrm{MJ} / \mathrm{kg}$.}

The performance indicator as thermal efficiency of the modified pressurized stove was determined through a calculation based on the fuel consumption to evaporate a known quantity of water. The experiments were carried out to measure the energy consumed for supplying suitable heat required to heat $5 \mathrm{~kg}$ of water to boiling point $\left(100{ }^{\circ} \mathrm{C}\right)$, sensible heat to heat the vessel to $100{ }^{\circ} \mathrm{C}$ and, heat of vaporization of a known quantity of water at $100{ }^{\circ} \mathrm{C}$ at atmospheric pressure and the heat of combustion of the fuel consumed. Thermal efficiency is calculated using the formula given below [4], [18], [19]:

$$
\eta_{\mathrm{T}}=\frac{\mathrm{m}_{\mathrm{w}} \times 4.186 \times \Delta \mathrm{T}+\mathrm{m}_{\mathrm{cv}} \times 2.257 \times 500 \times \Delta \mathrm{T}}{\mathrm{m}_{\mathrm{f}} \times \mathrm{HV}}
$$

where $\eta_{\mathrm{T}}$ is thermal efficiency $(\%) ; \Delta \mathrm{T}$, the temperature difference $\left({ }^{\circ} \mathrm{C}\right) ; \mathrm{m}_{\mathrm{CV}}$, the mass of vessel $(\mathrm{kg})$ and $\mathrm{m}_{\mathrm{f}}$ is the mass of fuel $(\mathrm{kg})$.

The vessel pressure, ignition temperature, flame temperature, height, and structure were observed during the experimentation. The vessel pressure was measured by a pressure gauge mounted on the fuel vessel. The readings are taken for the keeping vessel pressure up to maximum levels of 3 bar. The flame temperature was measured by using digital thermocouple Krisbow-KW06-283. The height and structure of flame were observed by visual for a certain period of time.

A droplet is a small particle of liquid having a more or less spherical shape and also known as particles. The process of generating a large number of droplets is called atomization. The high quality of atomization is an important prerequisite of good combustion. The liquid fuel combustion requires atomization of the fuel in the form of droplets using the spray (spoiler) nozzle. Good atomization qualities correspond to the number and diameter of droplets [20]. To determine these characteristics, the pressurized cooking oil stove is fed fuel from a vessel under pressure created by gravity and a hand pump. The readings were taken for the different vessel pressure levels of 0-3 bar by employing the regulating the oil valve. To light the stove, a small amount of alcohol burned in a spirited cup, where it warm up for about 30 seconds until the fuel vapor is ignited and the combustion process is initiated, the heat from the flame keeps the spiral pipeline hot enough to continue the vaporization process. The vessel pressure, flame temperature, height and structure of flame were observed. Visual observation of flame color and structure was done in every single time.

The difficulties in specifying the droplets diameter distribution in nozzle sprayer have led to widespread use of various mean droplets diameter. The various mean diameters may be determined from prediction equations that have been derived from theory or experiment. Therefore, it is important to decide which equation is the most suitable to be selected to predict droplet size of VCOs as fuel. The droplets diameter were predicted as the Sauter-mean-diameter (SMD model) produced by the atomization of sprayer nozzle (nozzle diameter, $\mathrm{D}_{\mathrm{n}}$ of $0,5 \mathrm{~mm}, 0,7 \mathrm{~mm}$ and $0,8 \mathrm{~mm}$ ) by using equation (6) [20], [21].

$$
\mathrm{d}_{\mathrm{m}}=2330 \times \rho_{\mathrm{L}}^{0,121} \times \mathrm{V}_{\mathrm{L}}^{0,131} \times \mathrm{P}_{\mathrm{v}}^{-0,135}
$$

where $d_{m}$ is droplets diameter $\left(\mu_{m}\right) ; \rho_{L}$ is oil density $\left(\mathrm{kg} / \mathrm{m}^{3}\right)$, and $\mathrm{P}_{\mathrm{v}}$ is the pressure vessel (bar)

\section{RESULTS AND DISCUSSIONS}

\section{E. Fuel Characteristic}

The fuel properties were characterized by density, kinematic viscosity, and heating value. The kinematic viscosity is the other key factor to take into account in order to achieve good fuel combustion. Because of the straight use of VCOs in pressurized stove entails adjusting several physical properties density and viscosity. In this work, the density and kinematic viscosity of the different VCOs were measured from $25{ }^{\circ} \mathrm{C}$ to $70{ }^{\circ} \mathrm{C}$ according to the method explained in above section and are shown in Table 2.

In Table 2 can be seen that the density and viscosity of each VCOs decrease with increase in the temperature. Toscano's work report [9], that the viscosity of fresh VCO is highest than other oils, related to the level of double bonds and the length of the hydrocarbon chain. The viscosity increases when the presence of double bonds decreases and when the length of the hydrocarbon chain increases. Table 1 and Table 2 shows that the value of UCO viscosity is quite near to the value of the kerosene viscosity studied for the range of temperatures analyzed.

\begin{tabular}{|c|c|c|c|c|}
\hline Fuel & $\begin{array}{c}\mathbf{T} \\
\left({ }^{\mathbf{O}} \mathbf{C}\right)\end{array}$ & $\begin{array}{c}\text { Density } \\
\mathrm{kg} / \mathrm{m}^{3}\end{array}$ & $\begin{array}{l}\text { Kinematic } \\
\text { viscosity } \\
(\mathrm{cSt})\end{array}$ & $\begin{array}{c}\text { Heating } \\
\text { Value } \\
\text { MJ/kg } \\
\text { (Avg) } \\
\end{array}$ \\
\hline \multirow[t]{3}{*}{ UCO } & 30 & 909 & 18.59 & \\
\hline & 50 & 898 & 16.43 & 38.28 \\
\hline & 70 & 867 & 15.19 & \\
\hline \multirow{3}{*}{$\begin{array}{l}\text { Crude } \\
\text { VCO }\end{array}$} & 30 & 900 & 17.13 & \\
\hline & 50 & 893 & 16.88 & 38.28 \\
\hline & 70 & 883 & 15.20 & \\
\hline \multirow[t]{3}{*}{ Fresh VCO } & 30 & 895 & 125.17 & \\
\hline & 50 & 884 & 117.71 & 39.69 \\
\hline & 70 & 874 & 115.02 & \\
\hline
\end{tabular}

TABLE II

DENSITY, Viscosity AND HEATING VALUe of $\mathrm{VCO}_{\mathrm{s}}$

During frying, various physical and chemical changes influence viscosity. Free fatty acid and some polymerized triglycerides which increase the molecular mass and reduce the viscosity of UCO [9], [12]. Both of density and viscosity are highly temperature sensitive and it is dependence between them. In this case, the viscosity which is calculated using equation (3) only match to the viscosity of fresh VCO. In other words, the equation is suitable to be used to calculate the viscosity of oils with a density lower than fresh VCO. 
The energy content (heating value) of the VCOs as presented in Table 2 has similar values to the energy content of kerosene (Table 1). This may be due to the similar in the chemical composition of the molecular structure of the oil. The heating value of oil is influenced by the length of the hydrocarbon chain, oxygen, and hydrogen content. The heating value of the fuel oil will decrease due to a reduction in the hydrogen content and the increase in the length of the chain, the carbon atoms and the number of double bonds [9].

In this work, these VCOs as alternative fuels were analyzed to have a high kinematic viscosity which makes them difficult to atomize well and thus affecting the combustion performance. However, by adequately heating to adjust the VCOs used as fuel properly, it is possible to improve their combustion performance.

\section{F. Droplets Diameter}

The kinematic viscosity of VCOs is one of the key parameters that affect the process of fuel atomization and evaporation (mist). The high kinematic viscosity of fuel will adverse effect on the combustion of VCOs, not only posing problems in the associated fuel supply line and fuel nozzle sprayer but also the distribution of droplet diameter (atomization). However, preheating of the fuel is one of the ways that reduce the kinematic viscosity to improve the atomization.

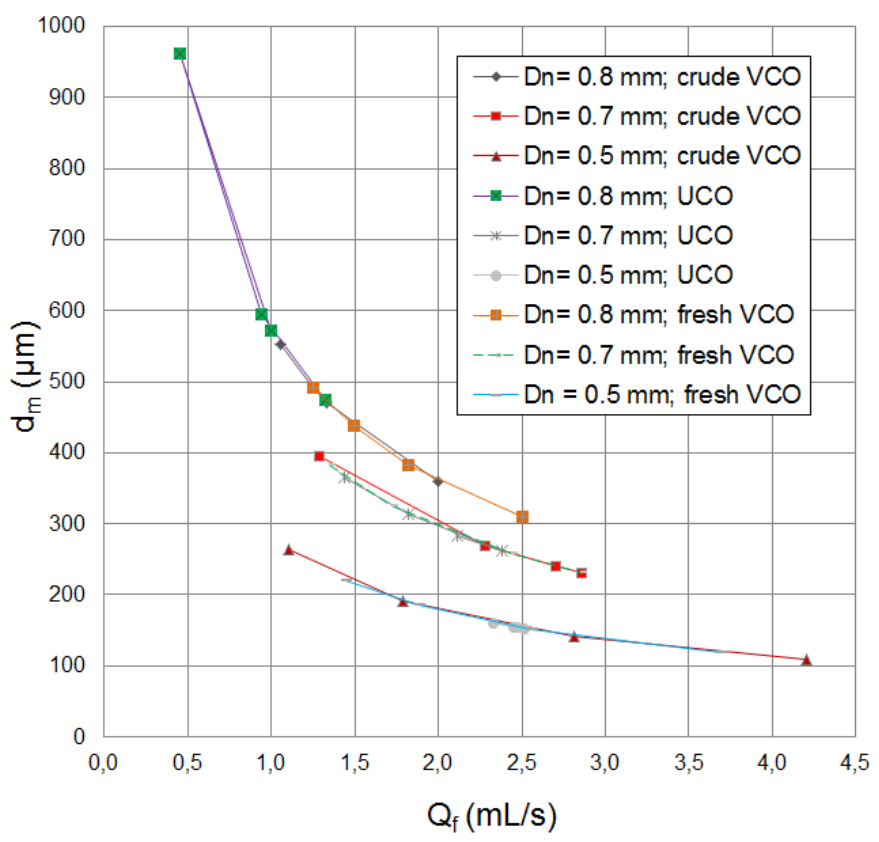

Fig. 2 Droplets diameter versus fuel flow rate

Atomization spray (droplets size) characteristics of the different VCOs available for combustion applications is one goal of this present study. Preheating was employed in spiral coil pipeline on a pressurized stove.

After conducting the experiments with three sizes of sprayer nozzle diameters (atomizer), the following results are obtained. Fig. 1 shows the graph of droplet diameter size, $\mathrm{d}_{\mathrm{m}}$ in $\mu \mathrm{m}$ of various VCOs versus fuel flow rate, $\mathrm{Q}_{\mathrm{f}}$ in $\mathrm{mL} / \mathrm{s}$. The variations of sprayer nozzle diameters with different flow rates increase would reduce the size of droplets diameter. The pressurization of VCOs as fuel in the vessel increases the density of air and allows for the fuel/air mixture to escape through a nozzle sprayer to ensure better atomization and also enhance fuel droplet vaporization and combustion. The diffusion rates of overall combustion reaction vary approximately with the pressure.

Atomization of VCOs produced oil droplets diameter of about $155 \mu \mathrm{m}-650 \mu \mathrm{m}$. UCO produced the smallest diameter of the particle that is $155.70 \mu \mathrm{m}$ by using nozzle diameter of $0.5 \mathrm{~mm}$. The crude VCO and fresh VCO have the larger diameter than UCO because of the fuel properties itself that affect the atomization process. The fuel properties such as density and viscosity cause unstable atomization and droplets diameter. Thus, the various VCOs gave the various droplet diameters [20], [21].

In this study, the larger diameter of nozzle produced the larger droplet diameter for all VCOs. This is because of the larger diameter of the nozzle, the less pressure on the nozzle that generated the less flow rate. The flow rate is a function of the pressure vessel that affects droplet diameter. The higher the pressure vessel that is injected, the smaller the droplet diameter produced due to the shorter of break-up time and the smaller break-up length. The study of this droplet diameter is useful to know the proper atomization process, so that will be gained the perfect combustion of VCO as fuel.

\section{G. Flame profile}

This work also showed that as the vessel pressure of the test VOPS increases, the flame temperature also increases. The reduction in viscosity of the VCOs with the increase in temperature would decrease the droplets diameter distribution. The heating of the VCOs makes it spray characteristics more like those of kerosene, which is a direct reduction of viscosity.

The higher flame temperatures due to the increasing rate of the combustion reaction, and reactant concentration caused by the higher pressure vessel. The higher vessel pressure could also increase the rate of combustion reactions by increasing the concentrations of the reactants to generate higher combustion temperatures with shorter and more compact flames [7].

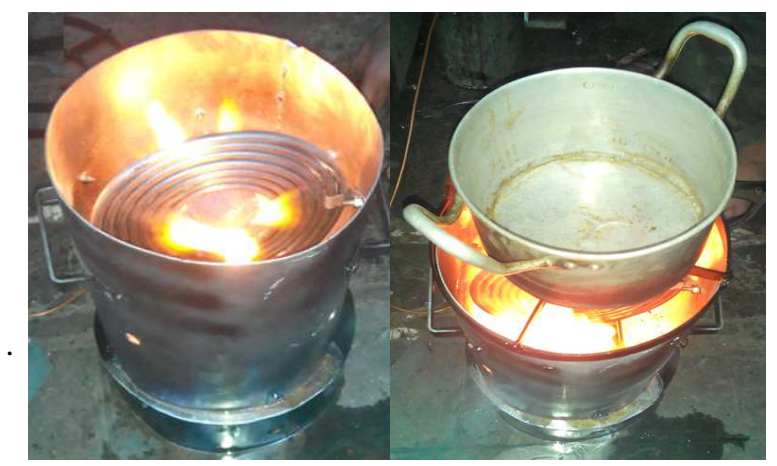

Fig. 3 Visualized flame

Fig. 3 is the sample of the flame profile of the VCOs burnt. The highest flame temperature of $1100^{\circ} \mathrm{C}$ in these experiments was achieved by burning UCO as fuel at fuel consumed rate (FCR) $1.14 \mathrm{~L} / \mathrm{hr}$ using this modified pressurized cooking stove. The higher flame temperature of 
UCO, in this case, could be ascribed to its relatively higher calorific value over other fuels and the high pressure is equivalent to high escape velocity and longer spray length, providing opportunity for the fuel to fully atomize and granting excess air access to the combustion process [7]-[9]. It is also understood because UCO produced the smallest diameter of the particle when compared with crude VCO and fresh VCO. The smaller droplet size would make a better mixing and perfect combustion.

Commonly, the VCOs could be burned in a red-bluish flame. UCO tended to produce transparent a yellow-blue flame. The decreased viscosity of VCOs produced higher flame temperature. Used VCOs as fuel could be burned with a minimum surface flame temperature of about $900{ }^{\circ} \mathrm{C}$.

\section{H. Combustion Performance and Economic Studies}

In this experiment, three kinds of VCOs were possible to be utilized as fuel using modified pressurized cooking stove with a small amount of alcohol to start up the ignition. The more usage of alcohol $(20 \mathrm{~mL})$ with the smallest diameter nozzle induced a shorter ignition time (about 3 seconds). The flash point of each VCOs was determined by a small amount $( \pm 5 \mathrm{~mL})$ of oil heated in a small pan on a hot plate until enough volatile compounds emerge from the oil that a bluish smoke becomes clearly visible. The lowest temperature at a barometric pressure when sufficient vapor mixture with the air starts to burn was measured as a flash point. When smoke emission becomes more intense, the oil temperature increases more rapidly close to its auto-ignition point. Table 3 shows the flash point of UCO, $182{ }^{\circ} \mathrm{C}$ is lowest than other oils. The flash point of VCOs is related to its viscosity. The viscosity of VCOs is related to the level of double bonds and the length of the hydrocarbon chain. The heating of UCO during frying would reduce the viscosity due to decrease the double bonds and the length of the hydrocarbon chain. The lower viscosity will reduce the flash point and ignition point of VCOs and it affects the burning quality of VCOs and affects its atomization

The performance of a fuel/VOPS/pot combination was characterized by a thermal efficiency and flame temperature. Revised calculation procedure of water-boiling test was used and some sets of experiments were repeated by keeping vessel pressure levels.

Flame temperature of the burning of VCOs tends to fluctuate over time due to the difficulty to keep constant of the pressure vessel level. The relatively constant surface flame temperatures would achieve after 25 minutes. Fig. 4 is an example of the flame profile of VCOs combustion. The results show UCO, crude VCO, and fresh UCO could be burned in a red-bluish flame with a maximum flame temperature of flue gases of $1100{ }^{\circ} \mathrm{C}, 1042{ }^{\circ} \mathrm{C}$, and $920^{\circ} \mathrm{C}$, respectively.

The UCO had the largest fuel consumption rate (FCR) compared to the crude VCO and fresh VCO due to its highest density and its highest fuel flow rate than other fuels. However, the utilized of UCO as fuel in this modified pressurized stove provided higher thermal efficiency than other fuels. This case is correlated with the higher energy content and a smaller droplet diameter of its fuel as presented in Table 2, Table 3 and Fig. 2.

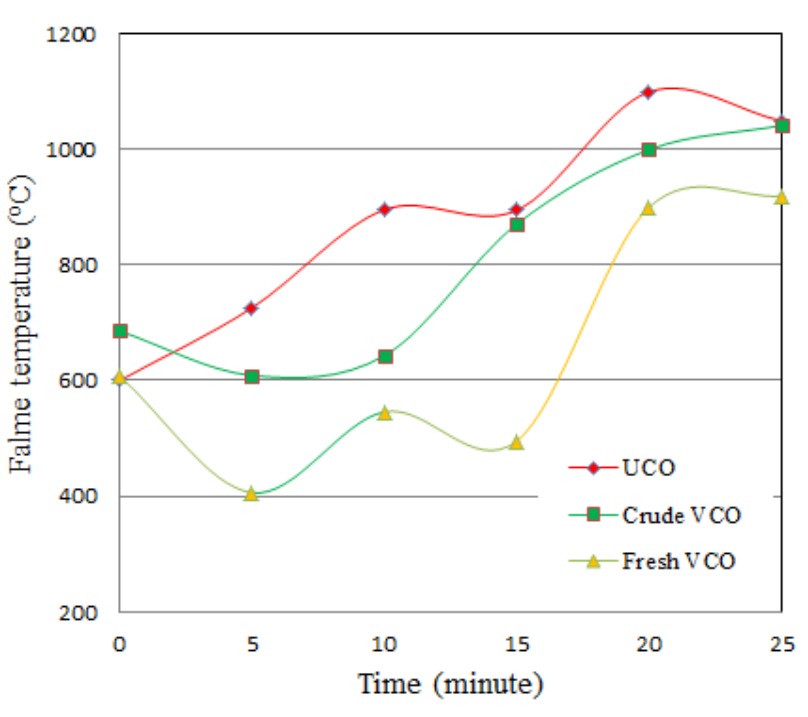

Fig. 4 Surface flame temperature

The VCOs fuels tested in VOPS by the fuel consumption rate (FCR) of $\pm 1.50 \mathrm{~L} / \mathrm{h}$ have an average of thermal efficiency of around $20 \%-32 \%$. The utilized of UCO as fuel in this modified pressurized stove provided highest thermal efficiency of $31.57 \%$. This value is close to the thermal efficiency with kerosene of about $30 \%$. As a comparison, Makonese [19] observed that vegetable oil showed $\pm 41 \%$ thermal efficiency compared to $\pm 30 \%$ thermal efficiency with kerosene. From these studies, it is clear that VCO gives an average more efficiency than kerosene with the VOPS due to the higher calorific of VCOs and good atomization of VCOs produced to have better combustion.

TABLE III

VOPS PERFORMANCE

\begin{tabular}{|c|c|c|c|c|c|c|}
\hline Fuel & $\begin{array}{c}\mathbf{D}_{\mathbf{n}} \\
(\mathbf{m m})\end{array}$ & $\begin{array}{c}\mathbf{Q}_{\mathbf{f}} \\
(\mathrm{mL} / \mathrm{s})\end{array}$ & $\begin{array}{c}\text { FCR } \\
(\mathbf{L} / \mathbf{h r})\end{array}$ & $\begin{array}{c}\text { Flash } \\
\text { point } \\
\left({ }^{\circ} \mathrm{C}\right)\end{array}$ & $\begin{array}{c}\eta_{\mathrm{T}} \\
(\%)\end{array}$ & $\begin{array}{c}\text { Cost } \\
(\text { IDR/hr })\end{array}$ \\
\hline \multirow[t]{3}{*}{ UCO } & 0.8 & 0.93 & 1.53 & & 22.39 & 3,068 \\
\hline & 0.7 & 1.94 & 1.17 & 182 & 31.63 & 2,340 \\
\hline & 0.5 & 2.44 & 1.16 & & 25.66 & 2,326 \\
\hline \multicolumn{2}{|c|}{ Average } & & 1.29 & & 26.56 & 2,578 \\
\hline \multirow{3}{*}{$\begin{array}{l}\text { Crude } \\
\text { VCO }\end{array}$} & 0.8 & 1.41 & 0.97 & & 17.85 & 10,749 \\
\hline & 0.7 & 2.28 & 1.31 & 215 & 25.33 & 14,445 \\
\hline & 0.5 & 2.48 & 1.02 & & 20.06 & 11,263 \\
\hline \multicolumn{2}{|c|}{ Average } & & 1.11 & & 21.08 & 12,153 \\
\hline \multirow{3}{*}{$\begin{array}{l}\text { Fresh } \\
\text { UCO }\end{array}$} & 0.8 & 1.77 & 1.27 & & 18.42 & 15,308 \\
\hline & 0.7 & 2.09 & 1.18 & 200 & 22.11 & 14,171 \\
\hline & 0.5 & 2.40 & 1.28 & & 21.26 & 15,408 \\
\hline \multicolumn{2}{|c|}{ Average } & & 1.25 & & 20.60 & 14,962 \\
\hline
\end{tabular}

In the current work, the economic was evaluated by boiling amount of water (from $25^{\circ} \mathrm{C}$ to about $100{ }^{\circ} \mathrm{C}$ ). The fuel consumption cost of the UCO utilization as fuel using this pressurized stove gave the most economical cost was IDR 2,578/hr rather than the use of two other VCOs. This value was still cheaper than the use of other fuels like kerosene. The price of kerosene was IDR 16,800/hr $18,200 / \mathrm{hr}$ at the fuel consumption rate of around $1.2 \mathrm{~L} / \mathrm{hr}-$ $1.3 \mathrm{~L} / \mathrm{hr}$ and the thermal efficiency of $45.84 \%$. Whereas the use of LPG price at the fuel consumption rate of around 0.5 
$\mathrm{kg} / \mathrm{hr}-0.6 \mathrm{~kg} / \mathrm{hr}$ with the thermal efficiency of $13.21 \%$ was IDR $3,600 / \mathrm{hr}-4,400 / \mathrm{hr}$.

\section{CONCLUSIONS}

The modified pressurized stove with spiral pipeline mechanism exposed, that serves as auto oil preheater and the burner spoiler nozzle to vaporize oil could reduce the fuel kinematic viscosity to improve the atomization process and to improve combustion performance.

Atomization of VCOs produced oil droplets diameter of about $155 \mu \mathrm{m}-650 \mu \mathrm{m}$. UCO produced the smallest diameter of the particle that is $155,70 \mu \mathrm{m}$ by using nozzle diameter of $0,5 \mathrm{~mm}$. UCO, crude VCO, and fresh UCO could be burned in a red-bluish flame with a maximum flame temperature of flue gases of $1100{ }^{\circ} \mathrm{C}, 1042{ }^{\circ} \mathrm{C}$ and $920^{\circ} \mathrm{C}$, respectively.

The utilized of UCO as fuel in this modified pressurized stove provided highest thermal efficiency of $31.57 \%$. UCO gave the most economical cost was IDR 2,578/hr rather than the use of two other VCOs and this value was still cheaper than the used kerosene and LPG. By the results of this study, small and medium industries in West Bandung District can be suggested to utilized UCO around 18 tons/year to substitute and to meet about $30 \mathrm{~kg} /$ day LPG needed in its production process.

\section{ACKNOWLEDGMENT}

The author would like to acknowledge the financial support from DRPM-RISTEKDIKTI sponsorship through the PUPT-Grant for the year 2016-2018. We also wish to make special reference to Mrs. Andisa Eka Ahyati and Mrs. Irawati for their technical support and cooperation during the experiment.

\section{REFERENCES}

[1] West Bandung District Government, "Medium-term Regional Development Plant of West Bandung District for the year 20132018", Bandung, 2013.

[2] N. Andarwulan, D. Gitapratiwi, A. Laillou, D. Fitriani, P. Hariyadi, M. P. Regina and M. Drajat, "Quality of vegetable oil prior to fortification is an important criteria to achieve a health impact", Nutrients, vol.6, pp. 5051-5060, Nov., 2014.

[3] H. Kamilah, M.A. Azmi, and T. A. Yang, "Knowledge, attitude and perception towards the consumption of waste cooking oil between suburban and rural communities", International Journal on Advanced Science, Engineering and Information Technology, Vol. 5, pp. 306310, Oct. 2015.

[4] Suhartono, B. D. Prasetyo and I. N. Azizah, "Synthetic Gas (syngas) production in downdraft corncob gasifier and its application as fuel using conventional (LPG) domestic stove", Journal Engineering and Applied Sciences, vol. 11, pp. 5238-5243, Apr. 2016.

[5] Shahid E. M, Jamal Y., Shah A. N, Rumzan N, and Munsha $\mathrm{M}$, "Effect of used cooking oil methyl ester on compression ignition engine", Journal of Quality and Technology Management vol. 8, pp. 91-104, Dec. 2012.
[6] Sjaffriadi, B. Nurachman, N. A. Sasongko, and M. Imron, "Waste cooking oil pressurized multi fuel stove" in Proc. National Seminar of Chemical Engineering of Parahyangan Catholic University, Bandung, Indonesia, Apr. 2012, pp.1-8.

[7] I.R. Ejilah, A. A.G. Olorunnishola and L.A.A Enyejo, "Comparative analysis of the combustion behavior of adulterated kerosene fuel samples in a pressurized cooking stove", Global Journal of Researches in Engineering Mechanical and Mechanics Engineering, vol.13, pp.35-43, 2013.

[8] S. Ramkumar and V. Kirubakaran, "Review on admission of preheated vegetable oil in C.I. Engine", Indian Journal of Science and Technology, vol. 9, pp.1-11, Jan. 2016.

[9] G. Toscano and E. Maldini, "Analysis of the physical and chemical characteristics of vegetable oils as fuel", J. of Ag. Eng. - Riv. di Ing. Agr., 3, pp.39-47, Feb. 2007.

[10] J.C. Blin. Brunchwig, A. Chapuis, O. Changotade, S. Sidibe, E Noumi and P. Girard, "Characteristic of vegetable oils for use as fuel in stationary diesel engines towards specifications for standard in West Africa", Renewable and Sustainable Energy Reviews, vol.22, pp. 580-597, 2013.

[11] K. Naima and A. Liazid. Waste oils as alternative fuel for diesel engine: A Review, Journal of Petroleum Technology and Alternative Fuels vol.4, pp. 30-43, Marc.2013.

[12] F. Azima, Novelina and Rini, " Chemical characteristic and fatty acid profile in rendang Minangkabau, International Journal on Advanced Science, Engineering and Information Technology, Vol. 6, pp. 465468, Nov. 2015.

[13] A. A. Oluwafunmilayo, E.A. Samuel, O. A. Ayobami, "A Laboratory study of the effect of temperature on densities and viscosities of binary and ternary blends of soybean oil, soy biodiesel and petroleum diesel oil", Advances in Chemical Engineering and Science, vol. 2, pp. 444-452, Oct. 2012.

[14] A. Yadav and P. C. Jha, "A case study on biofuel stove technology; jatropha as a biofuel", International Journal Of Technology Enhancements and Emerging Engineering Research, vol. 1, pp.1418, 2013.

[15] M. Kratzeisen, and J. Muller, "Influence of free fatty acid content of coconut oil on deposit and performance of plant oil pressure stoves", Fuel, vol.89, pp. 1583-1589, Apr. 2010.

[16] B. Diyabi., T. Li and A. Cunliffe, "Evaluation of the effect of fuel properties on the fuel spray and jet characteristics in a HGV DI diesel engine operated by used cooking oils", Applied Mechanics and Materials, Vol. 694, pp. 3-12, 2014.

[17] A. Demirbas, "Relationship derived from physical properties of vegetables oil and biodiesel fuels", Fuel, vol. 87, pp.1743-1748, 2008.

[18] R. Natarajan, N.S. Karthikeyan, A. Agarwaal and K. Sathiyanarayanan, "Use of vegetable oil as fuel to improve the efficiency of cooking stove", Renewable Energy, vol. 33, pp.24232427, Jan. 2008.

[19] T. Makonese, C.P. Pigott, D. Kimemia, J. Robinson and H. Annegarn, "Performance evaluation and emission characterization of three kerosene stoves using a heterogeneous stove testing protocol (HTP)", Energy for Sustainable Development, vol. 16, pp. 344-351, Jul. 2012.

[20] J. Patra, A. Basak, A. Datta, R. Ganguly and S. Sen, "Characterization of straight vegetable oil sprays issued from pressure swirl and twin-fluid atomizer", International Journal of Emerging Technology and Advanced Engineering, vol. 3, pp.472478, Feb. 2013.

[21] A. Balabel and S. Safwat, "A Theoretical model for predicting the mean droplet diameter in spray based on the linear stability analysis, International journal of control, automation and system, vo.2, pp.4146, Oct. 2013. 